Case Reports

\title{
Round Pneumonia in Adults Masquerading as Bronchogenic Carcinoma
}

\author{
${ }^{1}$ Chandan Kumar, ${ }^{2}$ Abhishek, ${ }^{3}$ Pal Satyajit Singh Athwal, \\ ${ }^{4}$ Shivangi Gupta, ${ }^{5}$ Fnu Kajal, ${ }^{6}$ Piyush Puri and ${ }^{7}$ Anil Kumar Kem \\ ${ }^{1,2,3,4,6,7}$ Department of Internal Medicine, Saraswathi Institute of Medical Sciences, Hapur (U.P), India \\ ${ }_{5}^{5}$ Additional Mission Director, National Health Mission, Uttar Pradesh, India
}

Article history

Received: 04-09-2018

Revised: $20-12-2018$

Accepted: 5-01-2019

Coressponding Author: Pal Satyajit Singh Athwal

Department of Internal Medicine,

Saraswathi Institute of Medical

Sciences, Hapur (U.P), India

Email: satyajitsinghathwal@gmail.com

\section{Introduction}

It is an oval shaped consolidation with nonsegmented pattern and centrifugal distribution. It is a rare variant comprising around $1 \%$ of pneumonia, the chest $\mathrm{x}$-ray finding of round pneumonia is even found in less than $1 \%$ cases of these round pneumonia (Porstmann, 1977). Greenfeild and Gyepes (1964), first described this variant mimicking as a bronchogenic carcinoma. Rose and Ward (1973), it was recognized as a clinical entity as round pneumonia. Unfamiliarity of this variant in adults can lead to extensive diagnostic work up like C.T scan or even biopsy in this benign condition which is just a consolidation opacity of infectious etiology.

\section{Case Report}

45-year-old female with history of chronic smoking about 20 pack a year presented with cough, fever, fatigue, since a week without any history of weight loss and no significant past history. On physical examination patient had fever, $\mathrm{BP}-124 / 82 \mathrm{mmHg}$, pulse rate was 100 bpm, respiratory rate: 23 breaths per minute, on auscultation fine crackles on left infra-axillary area were present. The rest of the examination was unremarkable. Chest X-ray-PA view revealed a round opacity with air bronchogram and infiltrates in left lung field (Fig. 1). Complete blood count reveals white count of $14 \times 10^{3}$ $\mathrm{mL}$, a hematocrit of $30 \%$, low hemoglobin of $9.0 \mathrm{~g} / \mathrm{dl}$ and normal platelet count. Liver and kidney functions were within the normal limit. Based on the acute history of presentation, patient was started on Injection ceftriaxone (i.v) 12 hourly for 10 days with tablet
Azithromycin $500 \mathrm{mg}$ once a day for 5 days. Patient become afebrile with remarkable decrease in frequency of cough noted on $3^{\text {rd }}$ day of starting antibiotics. Patient was discharged on $10^{\text {th }}$ day with repeat chest $\mathrm{x}$-ray on $18^{\text {th }}$ day demonstrated clearance of round opacity. She responded well to the antibiotics, so no further investigations were done.

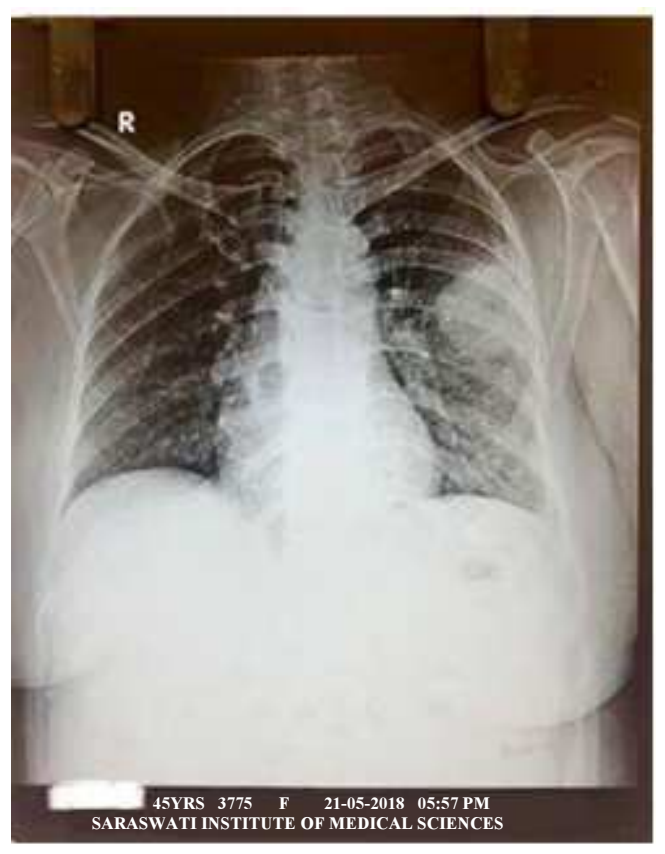

Fig. 1: X-ray chest PA view demonstrating round opacity with air bronchogram and infiltrate in left lung field 


\section{Discussion}

Pneumonia is a major health problem worldwide, which is the leading cause of death due to infectious diseases. On imaging it can present as bronchopneumonia, interstitial pattern or lobar consolidation. Round pneumonia a rare variant is common in children but rarely seen in adults (Taylor et al., 1978). Pathogenesis of round pneumonia is unknown, it is believed that atypical dissemination of the exudates through pores of Kohn (discrete holes in walls of alveoli) and channel of Lembert (connections between adjacent bronchioles and alveoli) is responsible for oval pattern on imaging (Soubani and Epstein, 1996). According to Zinkermagel et al. (2001) the round lesion on imaging is seen in earliest phase of disease due to slow velocity of exudative spread through pores of Kohno and Lambert's channel.

Patient with round pneumonia usually presents as community acquired pneumonia with benign course with fever and cough for 1-2 weeks along with leukocytosis. There is characteristic radiological and clinical response to course of antibiotics (Rose and Ward, 1973). In our case, patient clinical presentation and findings pointed toward an acute infectious pathology of lung parenchyma and coincidently financial constrains from patient's side led us to the diagnosis. The neoplastic and non-neoplastic condition of round lesions such as pulmonary nodule, atelectasis, bronchoalveolar sequestration obviously will show no improvement with course of antibiotics. Streptococcus pneumonia is the most common cause of round pneumonia (Zinkernagel et al., 2001). Other include Mycobacterium tuberculosis (acuteness of symptoms and no history of weight loss ruled it out on our case), Klebsiella pneumonia, Hemophilus influenza and some atypical like Chlamydia psitacci (Zylberman et al., 2006) and Coxiella burnetti (no authentic data of prevalence of $\mathrm{Q}$ fever in our area). According to Anton $\mathrm{Q}$ fever should be ruled out and round pneumonia should be treated with macrolides and fluoroquinolones (Anton, 2004). Wan et al. (2004) reported eight case of severe acute respiratory syndrome presented as round pneumonia, seven of these eight cases were having lesion in the right lung so this is also a rare presentation of severe respiratory distress syndrome. Etiological diagnosis of round pneumonia in our case was not possible because of limited laboratory facility in rural India. Considering Streptococcus pneumoniae being the most common etiological, we started ceftriaxone and azithromycin for atypical organisms. The radiological feature of round pneumonia could be from large lesion to small, according to Kohno et al., satellite lesion can be useful in diagnosing round pneumonia on computerized tomography. According to Zwirewich et al. (1991) air bronchograms are not useful to differentiate between benign or malignant lesion (the age adjusted incidence rate of malignant lesion is around 2 per 100000 population in western India) (Behra, 2017), air bronchograms can be found in eighty seven percent of malignant cases and in around half cases of pulmonary nodule which is a benign condition. C.T scan is more accurate in differentiating the lesions as compared to $\mathrm{x}$ ray. Misdiagnosis of round pneumonia can lead to sepsis which is one of leading cause of mortality in developing nations and unnecessary diagnostic procedures like computed tomography or even biopsy.

\section{Conclusion}

Round pneumonia is a rare presentation which is usually found on the right side and here we present coin lesion on the left side which can masquerade as carcinoma or other conditions. Recognition of the infectious etiology, a benign condition which can be managed with antimicrobial therapy at an early stage can prevent unnecessary aggressive diagnostic tests and simultaneously decreasing the cost of health care in resource poor settings.

\section{Acknowledgement}

The authors are thankful to Department of Radiology, Saraswathi Institute of Medical Sciences, Hapur for helping us with the radiological images used in this case report.

\section{Author's Contributions}

Chandan Kumar: Involved in drafting the manuscript. Final approval for publication. Edited the content for critical information. Analysis and interpretation of data.

Abhishek: Involved in drafting the manuscript. Final approval for publication. Edited the content for critical information. Analysis and interpretation of data.

Pal Satyajit Singh Athwal: Involved in drafting the manuscript. Final approval for publication. Edited the content for critical information. Analysis and interpretation of data.

Shivangi Gupta: Involved in drafting the manuscript. Final approval for publication. Edited the content for critical information. Analysis and interpretation of data.

Fnu Kajal: Revised the manuscript for critical information, analysis and interpretation of data. Final approval for publication. Involved in drafting the manuscript.

Piyush Puri: Involved in drafting the manuscript. Final approval for publication. Edited the content for critical information. Analysis and interpretation of data.

Anil Kumar Kem: Revised the manuscript for critical information. 


\section{Ethics}

Written informed consent was obtained from the patient for this case report and the images.

\section{References}

Anton, E., 2004. A frequent error in etiology of round pneumonia. Chest, 125: 1592-1593. DOI: $10.1378 /$ chest.125.4.1592

Behra, D., 2017. Lung cancer in India: Challenges and perspectives. J. Thoracic Onchol., 12: 114-115. DOI: $10.1016 /$ j.jtho.2016.11.101

Greenfield, H. and M.T. Gyepes, 1964. Oval-shaped consolidation simulating new growth of the lung. Am. J. Roentgenol. Radium Ther. Nucl. Med., 91: 125-31. PMID: 14113756

Porstmann, W., 1977. Therapeutic Embolization of Arteriovenous Pulmonary Fistula by Catheter Technique. In: Current Concepts in Pediatric Radiology, Kelop, O. (Ed.), Springer, Berlin, pp: 23-31.

Rose, R.W. and B.H. Ward, 1973. Spherical pneumonias in children simulating pulmonary and mediastinal masses. Radiology, 106: 179-82. DOI: $10.1148 / 106.1 .176$

Soubani, A.O. and S.K. Epstein, 1996. Life-threatening "round pneumonia". Am. J. Emerg. Med., 14: 189-191. DOI: 10.1016/S0735-6757(96)90132-1
Taylor, B.G. E.M. Cockerill, F. Manfredi and E.C. Klatte, 1978. Therapeutic embolization of the pulmonary artery in pulmonary arteriovenous fistula. Am. J. Med, 64: 360-365. DOI: $10.1016 / 0002-9343(78) 90066-9$

Wan, Y.L., H.P. Kou, Y.H. Tsai, Y.K. Wu and C.H. Wang et al., 2004. Eight cases of severe acute respiratory syndrome presenting as round pneumonia. Am. J. Roentgenol., 182: 1567-1570. DOI: 10.2214/ajr.182.6.1821567

Zinkernagel, A.S., A. Schaffner and A. Himmelman, 2001. Photo quiz. Round pneumonia due to Streptococcus pneumonia. Clin. Infect. Dis., 32: 1233-1234. DOI: 10.1086/319761

Zylberman, M., E. Cordova and G. Farance, 2006. Round pneumonia in adults, an unusual presentation of lung parenchyma infection: A report of two cases and review of the literature. Clin. Pulmonary Med., 13: 229-231.

DOI: 10.1097/01.rlu.0000249628.58514.fd

Zwirewich, C.V., S. Vedal, R.R. Miller and N.L. Muller, 1991. Solitary pulmonary nodule: high-resolution CT and radiologic-pathologic correlation. Radiology, 179: 469-76. 